Canadian University Music Review

Canadian University Music Review

Revue de musique des universités canadiennes

\title{
Sonic and Parametrical Entities in Tetras: An Analytical Approach to the Music of Iannis Xenakis
}

\section{James Harley}

Volume 16, numéro 2, 1996

URI : https://id.erudit.org/iderudit/1014426ar

DOI : https://doi.org/10.7202/1014426ar

Aller au sommaire du numéro

\section{Éditeur(s)}

Canadian University Music Society / Société de musique des universités canadiennes

ISSN

0710-0353 (imprimé)

2291-2436 (numérique)

Découvrir la revue

Citer cet article

Harley, J. (1996). Sonic and Parametrical Entities in Tetras: An Analytical Approach to the Music of Iannis Xenakis. Canadian University Music Review / Revue de musique des universités canadiennes, 16(2), 72-99.

https://doi.org/10.7202/1014426ar
Résumé de l'article

From his earliest works, Xenakis has conceived his music in terms of textures and sound masses. The analytical approach introduced here for a study of the recent string quartet, Tetras, takes such sonic entities as its point of departure. The inside-time structure is described in terms of the temporal succession of these entities and the outside-time relationships established between them by means of a whole range of parametrical entities. While the sonic and parametrical entities need to be specified for each piece, it is shown that this approach can be profitably applied to the complete Xenakis oeuvre.
All Rights Reserved ( C Canadian University Music Society / Société de musique des universités canadiennes, 1996
Ce document est protégé par la loi sur le droit d'auteur. L'utilisation des services d'Érudit (y compris la reproduction) est assujettie à sa politique d'utilisation que vous pouvez consulter en ligne.

https://apropos.erudit.org/fr/usagers/politique-dutilisation/ 


\title{
SONIC AND PARAMETRICAL ENTITIES IN TETRAS: AN ANALYTICAL APPROACH TO THE MUSIC OF IANNIS XENAKIS
}

\author{
James Harley
}

\section{Introduction ${ }^{1}$}

Iannis Xenakis is one of the most original and influential composers of our time. ${ }^{2}$ His prodigious output of the past forty years numbers over 130 works, from Metastasis ${ }^{3}$ of 1953-54 to Sea Nymphs of 1994, and continues at a remarkable rate. Xenakis has also written extensively about his own music and theory of composition, as well as on a wide range of other subjects. ${ }^{4}$

Given the widespread impact his work has had on composers, musicians, and audiences since the $1950 \mathrm{~s}$, it is surprising to learn how little his music has actually been analysed. A number of studies examine the early compositions and techniques, particularly those discussed by Xenakis himself in Formalized Music, ${ }^{5}$ but few carry on from there to concern themselves with more recent works and technical concerns. ${ }^{6}$ There are some understandable reasons for the

1 An earlier version of this paper was presented at the 1993 Annual Conference of the Canadian University Music Society in Ottawa. I am grateful to Mary Cyr and her two reviewers for their comments and suggestions.

2His seventieth birthday (1992) was celebrated with hundreds of performances around the world, including the "Semaine Xenakis" held in Montreal in April 1993, a collaboration of The Nouvel Ensemble Moderne, McGill University, the Université de Montréal, le Musée d'Art Contemporain, and CBC/Radio-Canada.

3 Xenakis considers Metastasis to be his first major work, and the riotous reception its premiere provoked at the Donaveschingen Festival in 1955 certainly catapulted him into the public spotlight. In fact, though, he had composed a number of works prior to this. These early pieces are catalogued and discussed in Francois-Bemard Mâche, "The Hellenism of Xenakis," Contemporary Music Review 8, Part 1 (1993): 197-211.

4His most important text is Formalized Music: Thought and Mathematics in Composition, rev. ed. (Stuyvesant, N.Y.: Pendragon Press, 1992); first published in English in 1971 (Bloomington: Indiana University Press); chaps. 1-6 first published in French as Musiques formelles: nouveaux principes formels de composition musicale (Paris: La Revue Musicale, 1963). The most comprehensive Xenakis bibliography (including his own writings) can be found in Henning Lohner, "Auswahlbibliographie," in Iannis Xenakis, ed. Heinz-Klaus Metzger and Rainer Riehn, Musik-Konzepte, 54/55 (Munich: Edition Text + Kritik, 1987), 169-91.

5 See Thomas Delio, "The Dialectics of Structure and Materials: Iannis Xenakis' Nomos Alpha," Journal of Music Theory 24, no. 1 (1980): 63-96; Gilles Naud, "Aperçus d'une analyse semiologique de Nomos Alpha," Musique en jeu 17 (1975): 63-72; Louise Paquette, Xenakis et la formalisation de la pensée musicale (Master's thesis, Universite de Montreal, 1980); Gwyneth Roberts, Procedures for Analysis of Sound Masses (Doctoral dissertation, Indiana University, 1978); Rosalie Sward, An Examination of the Mathematical Systems Used in Selected Compositions of Milton Babbitt and Iannis Xenakis (Doctoral dissertation, Northwestern University, 1981); Femand Vandenbogaerde, "Analyse de 'Nomos Alpha' de Iannis Xenakis," Mathématiques et Sciences Humaines 24 (1968): 19-34; Jan Vriend, “'Nomos Alpha' for Violoncello Solo (Xenakis 1966): Analysis and Comments," Interface 10 (1981): 15-82.

6 See Rudolf Frisius, "Konstruktion als Chiffrierte Information: Zur Musik von Iannis Xenakis," in Iannis Xenakis, ed. Heinz-Klaus Metzger and Rainer Riehn, 91-160; Harry Halbreich, "Da 'Cendrées' a 
avoidance of Xenakis' music on the part of analysts and theorists, which will be discussed below. Not least of these is the fact that since Formalized Music was first published in 1971, Xenakis has been reticent to discuss in detail any of his subsequent compositions. ${ }^{7}$ However, those barriers have not been strong enough to hold back the expressive force of his work, so it follows, therefore, that there must be ways of developing a "proper critical response"8 to the music.

The analytical approach proposed in this article takes as its starting point the notion of the sonic entity, fundamental to Xenakis' compositional aesthetic, and attempts to build a conceptual-perceptual understanding of the music on the basis of the characteristics of these entities and the relational space established between them by means of generalized parametrical entities. ${ }^{9}$ The work discussed here, Tetras, for string quartet, has been chosen for a number of reasons: it has been widely performed, ${ }^{10}$ is available on disc, ${ }^{11}$ and is representative, as much as any one piece can ever be, of Xenakis' mature style. In addition, aside from concert reviews, Tetras been little discussed in print, ${ }^{12}$ and is certainly worthy of attention as being a major contribution to the quartet idiom.

\section{Background}

The fierce originality of Xenakis' music is the result of a remarkable confluence of interests, abilities, and experiences. In the first place, he is Greek, and was raised in Rumania and Greece, far from the cultural centres of Western Europe. ${ }^{13}$ Culturally, Xenakis was attracted to the era of Greek antiquity,

\footnotetext{
'Waarg': quindici anni di creatività," trans. Giorgio Pugliaro, in Xenakis, ed. Enzo Restagno (Torino: EDT Edizioni, 1988), 211-70; Maria Anna Harley, "Spatial Sound Movement in the Instrumental Music of Iannis Xenakis," forthcoming in Interface: Journal of New Music Research 23, no. 3 (1994); Ellen Rennie Flint, "Metabolae, Arborescences and the Reconstruction of Time in Iannis Xenakis' Psappha," Contemporary Music Review 7, no. 2 (1993): 221-48. Reference to briefer articles may be found in Lohner, "Auswahlbibliographie."
}

7 He has, however, been very generous in making his sketches available to those who do show serious interest in his work. See, for example, Flint, "Metabolae"; Harley, "Spatial Sound Movement"; Marc Couroux, "Dompter la mer sauvage: reflections sur 'Evryali' de Iannis Xenakis," forthcoming in Circuit: revue nord-américaine de musique du XX Siècle 5, no. 2 (1994).

8Edward T. Cone, "Mr. Cone Replies [to David Lewin's 'Behind the Beyond']," Perspectives of New Music 7, no. 2 (1969): 72. Cone's original article is "Beyond Analysis," Perspectives of New Music 6, no. 1 (1967): 33-51.

9For other analytical discussions of Xenakis which focus on the parametrical aspects of his music, see: Vriend, "Valse Stochastique?" in Regards sur lannis Xenakis (Paris: Stock, 1981), 132-49; Leigh Landy, What's the Matter with Today's Experimental Music? Organized Sound Too Rarely Heard (Chur, Switzerland: Harwood Academic Publishers, 1991), 8-16, 217-24.

10Apart from the Arditti Quartet, for whom Tetras was written, only a few quartets have actually attempted the work, including the Kronos Quartet and the Quatuor Danel. The work's dedicatees, however, have given hundreds of performances around the world (their most recent performance in Canada was in Toronto in March 1992).

11 Tetras can be found on two recordings, both by the Arditti Quartet: Arditti (London: Gramavision R2 79440, 1989); Iannis Xenakis: musique de chambre (1955-1990) pour cordes, piano, cordes et piano (Paris: Disques Montaigne 782005, 1992).

12 See Halbreich, "Da 'Cendrées' a 'Waarg', "253-55.

13 Biographical information can be found in Nouritza Matossian, Xenakis (London: Kahn \& Averill, 
drawing great inspiration from classical literature and philosophy (including Greek and Byzantine theories of music). ${ }^{14}$ Xenakis studied music, off and on, from an early age, but never pursued full-time musical training at a conservatory or university. These three elements, the geographical isolation, the preoccupation with a distant, "ideal" era, and the lack of formal musical training, contributed to Xenakis' estrangement both from the Western European "classical" music tradition and from contemporary developments. Consequently, it has been difficult to apply common analytical tools to his stylistically isolated work.

It is also important for an understanding of the music of Xenakis to take into account his formal studies in civil engineering at the Athens Polytechnic and his experience working as an engineer, and later as an architectural assistant, for Le Corbusier. The engineering studies cultivated in Xenakis a strong, technically-based concern for the materials used in a project, for the relationships between those materials, and the forms they give rise to. Engineers make use of detailed mathematical procedures for calculating all of the elements which could affect the construction of a work, and such a working method was quite natural for Xenakis when he turned to creating music. In addition, the work with Le Corbusier, an innovative architect with a particular concern for geometrical forms and natural proportions, ${ }^{15}$ gave Xenakis experience in applying his technical expertise to creative spatial forms. The engineer is trained to express qualities and relationships in mathematical terms, and the architect is trained to create forms based on proportions and carefully selected materials. These factors are decisive in tracing Xenakis' concern with sonic entities and outside-time structures, as well as for providing some explanation for the formidable arsenal of mathematical tools Xenakis has made use of in his compositional work.

Two other influences have also combined to orient Xenakis' musical aesthetic towards novel musical materials (particularly textures of "noise" elements and "sound masses"). The first is an attraction to the often dense and unpredictable sounds of nature, such as the wind, rain, or cicadas, as well as to natural phenomena such as the movement of clouds, rock formations and so on. ${ }^{16}$ The second influence, more emotionally charged, comes from the experience of participating in political demonstrations in the 1940s during the resistance in Athens against the occupying forces. The following passage is worth quoting at length for its terse portrayal of not only an

1986), first published in French as lannis Xenakis (Paris: Fayard, 1981).

14The political situation in Greece during his youth certainly contributed to this fascination, with the rejection by young intellectuals of many of the conflicting and confusing elements shaping Greek society at that time. Xenakis has continued to draw on this classical inspiration throughout his career, composing a number of pieces utilizing ancient Greek texts. The most recent of these is The Bacchae (Euripides), premiered in 1993 by the Opera Factory, London.

15 See Le Corbusier (C.E. Jeanneret-Gris), Modulor I and II, trans. Peter de Francia and Anna Bostock (Cambridge, Mass: Harvard University Press, 1980); first published in French as Le Modulor (1950) and Modulor 2 (1955).

16Matossian, Xenakis, 58. 
important source of sonic material but also of a crucial source of the expressive intensity of Xenakis' music:

Everyone has observed the sonic phenomena of a political crowd of dozens or hundreds of thousands of people. The human river shouts a slogan in a uniform rhythm. Then another slogan springs from the head of the demonstration; it spreads towards the tail, replacing the first...The clamour fills the city, and the inhibiting force of voice and rhythm reaches a climax. It is an event of great power and beauty in its ferocity. Then ... the perfect rhythm of the last slogan breaks up in a huge cluster of chaotic shouts, which also spreads to the tail. Imagine, in addition, the reports of dozens of machine guns and the whistle of bullets adding their punctuations to this total disorder ... [A]fter sonic and visual hell follows a detonating calm, full of despair, dust, and death. ${ }^{17}$

In searching for the technical means to realize such sonic entities in music, Xenakis found himself drawing on tools adapted from the domain of probability theory, a mathematical discipline used to analyse and manipulate global entities where individual elements are too numerous to track (e.g., the molecular motion in gases). Xenakis gradually developed what he would come to call stochastic music. ${ }^{18}$ The discipline of attempting to express music in logical-mathematical terms ultimately enabled Xenakis to create his own highly original sonic universe.

All of the elements discussed above-the isolation, the training as an engineer, the architectural experience, the complex sounds and processes of nature and of humanity, and the advanced mathematical tools-contribute to the creation of a body of musical work as unique in the history of music as that of any other composer. At the same time however, and for the same reasons, ordinary tools of analysis are rarely able to be fruitfully applied to this music. It is necessary to develop tools which take account of the general compositional techniques outlined by the composer and the sonic entities serving as the composer's point of departure for the creation of his music.

\section{Proportion, Time, Coherence}

Xenakis' background in engineering and architecture taught him the importance of proportion as a fundamental element of form. Proportion is defined as "the comparative relation in size, amount, etc. between things," as well as being concerned with "balance or symmetry." 19 Beyond an aesthetically-based sense of proportion, it is possible to express the relations between elements in precise terms by means of mathematics. ${ }^{20}$ Inspired by complex phenomena drawn from

17 Xenakis, Formalized Music, 9.

18 “'Stochastics' studies and formulates the law of large numbers, ... the laws of rare events, the different aleatory procedures, etc. ... I originated in 1954 a music constructed from the principle of indeterminism; two years later I named it 'Stochastic Music'." Ibid., 8.

19 Webster's New World Dictionary, Second College Edition (Toronto: The World Publishing Company, 1971).

20 Indeed, mathematics is defined as "the science dealing with quantities, forms, etc. and their relationships by the use of numbers and symbols," Webster's New World Dictionary. 
nature, politics, and so forth, Xenakis struggled, both in his work as architect and as composer, to find the mathematical tools to describe and manipulate the materials and their relationships within the complex entities that he himself wanted to create. He was aiming to go beyond the specifics of one domain or the other in order to derive general principles of structure which could be applied to any creative endeavour: "An identity of approach to architecture and music is the key to Xenakis' creative awakening and therefore the best way to understand his work in both areas. ... In architecture he could develop ideas by articulating them in space, while in music he could arrange them in time."21

In grappling with questions of proportion, particularly as manifest in a temporal domain such as music, Xenakis has determined three structural types which govern our perception of entities expressed in time: (1) outside-time, (2) temporal, and (3) inside-time structures. ${ }^{22}$ Outside-time structures represent an aggregate of quantifiable sonic characteristics (e.g., pitch, intensity, duration) which are not temporal. Temporal structures represent intervals of time which can be ordered independently of the sonic entities. Inside-time structures represent the correspondences and functional relations between the elements of the outside-time and temporal structures. ${ }^{23}$ Xenakis has developed independent techniques ("algebras") for organizing these structures and for combining them. The notion that sonic entities can be conceived of independently of time is perhaps Xenakis' most important contribution to compositional theory. Indeed, one of his main criticisms of serial music (the dominant force in contemporary music at the time) is that it is almost totally dependent on temporal and inside-time structures. ${ }^{24}$

Xenakis, then, had developed generalized principles for the creation and manipulation of complex textures and structural proportions (based on techniques adapted from probability theory and formal algebra) and had arrived at a non-linear conception of time which opened up new possibilities in the domain of musical form. What remained was to discover the means for unifying all of these elements of his compositional theory, to achieve some measure of coherence, both conceptually and musically. Xenakis accomplished this by means of the mathematical theory of groups. Basically, group theory enables various collections of entities (sets) to be combined in limited

21 Matossian, Xenakis, 55.

22Xenakis, Formalized Music, 160-61. The definition of these structures was influenced by Piaget's studies of the developmental stages in the child's conception of time. See Jean Piaget, The Child's Conception of Time, trans. A. J. Pomerans (New York: Ballantine Books, 1969); first published as Le développement de la notion du temps chez l'enfant (Paris: Presses Universitaires de France, 1946).

23Xenakis, Formalized Music, 160-61. This discussion is also indebted to the lucid explanation of these concepts given in Flint, "Reconstruction of Time," 221-23. See also Iannis Xenakis, "Le Temps en musique," Spirales 10 (1981): 9-11; Iannis Xenakis, "Regarding Time," Perspectives of New Music 27, no. 1 (1989): 84-92.

$24 \mathrm{~A} 12$-tone row, for example, is nothing more than an inside-time ordering of the chromatic scale and, with limited means for transformation, is extremely limited as source material for a piece of music. In comparison, tonal music, which uses a diatonic scale as an outside-time generative structure, is much less limited in its combinational possibilities as the elements of the scale can be ordered much more freely. See Xenakis, "La crise de la musique sérielle," Gravesaner Blätter 1 (July 1956): 2-4; Zaplitny, "Conversation," 96. 
ways. ${ }^{25}$ For example, group theory gave Xenakis the ability to establish correspondences between the highly contrasting outside-time (multi-dimensional, vectorial) and temporal (linear, commutative) structures. In this way, he was able to create a coherent form while drawing on a wide range of materials and techniques. Having tried to search out the most general principles underlying creative construction, principles of proportion, time, and coherence, Xenakis found a way to narrow in on specific techniques to limit the vast range of possibilities he had uncovered. ${ }^{26}$

\section{Outside-Time Structures}

The point of departure for the analytical approach outlined here is the sonic entity. According to Xenakis' taxonomy, the sonic entity is understood as having an outside-time structure. Therefore, the sonic entity, in itself rather abstract, can be delineated in terms of a multi-dimensional vectorial space, where each vector represents one parameter (e.g., pitch, amplitude, duration) describing a particular aspect of the entity. Each parameter, then, can be treated independently of the others, although it is important to remember that the placement in a precise temporal succession of events, variations of parameters, etc. is the separate concern of the temporal and inside-time domains. Obviously, traditional music can be thought of in the same terms, and Xenakis does actually give a vectorial representation of part of a Beethoven sonata in his chapter on "Symbolic Music" in Formalized Music. ${ }^{27}$ However, the notion of sonic entity can be extended beyond the notes and chords which form the basis of traditional music to more complex sonic entities which Xenakis describes as "textures." It is such entities as these that often form the structural basis for his music, and he acknowledges their importance in the preface to one of his scores, Phlegra (1975): "I am pursuing here the construction of textures and their organization on a higher level. I mean textures in the broader context of form.... Textures as pertaining to formal design are the corner-stone of art and knowledge."28

Before turning to Tetras, it may be instructive to look at an example taken from the outside-time organization of an earlier piece, Nomos Alpha (1966) for solo 'cello. ${ }^{29}$ For this piece, Xenakis defined eight basic "textures:" (1) ataxic cloud of sound-points; (2) relatively ordered ascending or descending cloud of sound-points; (3) relatively ordered cloud of sound-points, neither ascending nor descending; (4) ataxic field of sliding sounds; (5) relatively ordered

25Xenakis gives a detailed example of one application of group theory techniques in his analysis of Nomos Alpha (1966) for solo cello. Xenakis, Formalized Music, 209-36.

26 As Matossian puts it, "Xenakis' path entailed changes of level by taking him beyond music to structures and processes, then through mathematics back to music with this new information. By this shift in level he enriched the most important aspect of artistic invention, the act of transformation" (Matossian, Xenakis, 106-7).

27 Xenakis, Formalized Music, 164-65.

28 "Je poursuis ici la construction de textures et leur organisation sur un plan au-dessus. Je dis textures au sens general de la forme. ... Les textures au sens de la forme sont la clef de voûte de l'art et de la connaissance." Xenakis, preface to Phlegra (Paris: Éditions Salabert, 1975).

29 The score for Nomos Alpha is published by Boosey \& Hawkes Music Publishers, London. 
ascending or descending field of sliding sounds; (6) relatively ordered field of sliding sounds, neither ascending nor descending; (7) atom, represented on a 'cello by interferences of a quasi-unison; and (8) ionized atom, represented by interferences, accompanied by pizzicati. He also defined ten ways of playing the instrument (timbres): (1) pizzicato; (2) struck with the wood of the bow; (3) normal arco; (4) pizzicato-glissando; (5) normal arco with tremolo; (6) harmonic sound; (7) harmonic sound with tremolo; (8) arco sul ponticello; (9) arco sul pont. tremolo; and (10) arco with interferences. And, in addition, he defined four registral areas (treated separately from the element of pitch): (1) extremely high; (2) medium high; (3) medium low; (4) extremely low. ${ }^{30}$ The first category, the "textures," are the primary sonic entities of the piece. Note though, that with the exception of the last two which are quite specific with regard to timbre, these entities are very abstract, that is, they must be combined with the other parameters (timbre, register, duration, intensity, etc.) in order to be manifested as music. The number of possible combinations of textures with the various parameters is vast (leaving aside any specificities with regard to texture and timbre, the three categories listed above can give $8 \times 10 \times 4=320$ different couplings). Using techniques adapted from the theory of groups, Xenakis organized the various elements into subgroups (e.g., density-intensityduration, register-timbre) in order to limit the possibilities, and then constructed selection mechanisms for ordering successions of combinations of these subgroups to finally arrive at an inside-time structure which could form the basis for the finished score.

In Formalized Music, Xenakis gives a detailed description of the elaborate compositional process used for the creation of Nomos Alpha. ${ }^{31} \mathrm{He}$ would never again be so forthcoming about his working methods, although he has discussed more recently developed techniques such as the generation of melodic contours on the basis of Brownian motion ("random walks"), ${ }^{32}$ arborescences, a generalization of imitative counterpoint derived from transformation techniques using complex variables, ${ }^{33}$ and sieve theory, an algebraic method for the construction and manipulation of intervallic structures (of pitch, duration, etc.). ${ }^{34}$ However, a rigorous, reconstructive analysis of a work composed on the basis of any of these techniques, all of them drawing on mathematical tools in one way or another, would require detailed information which could only come from documentation provided by the composer (i.e., could not be derived directly from the score). After Nomos Alpha, that has not generally been possible. Therefore, it remains for us to approach the music on the basis of

30 Xenakis, Formalized Music, 222-24. It should be noted that the elements of pitch, density, duration, and intensity are also organized on the basis of outside-time structures.

31 Xenakis, Formalized Music, 209-36.

32Matossian, Xenakis, 230-31. This technique is an extension into the instrumental domain of Xenakis' method of digital sound synthesis on the basis of probability functions (Xenakis, Formalized Music, 242-54).

33Zaplitny, "Conversation," 100-101; James Harley, lecture notes from Xenakis Seminar on Aesthetics, Université de Paris, 1986.

34 Xenakis, "Sieves," Perspectives of New Music 28, no. 1 (1990): 58-78 [also included as Chapter 11 of the revised edition of Formalized Music (1992)]. 
what we know about Xenakis' work, that is, that his conception of music is architectural, ${ }^{35}$ that outside-time structures, in particular the definition of sonic entities, are of primary importance, and that group theory-derived combinatorial techniques are used to "manifest" these entities in time by means of parametrical variation and temporal ordering.

In what follows, the concepts and techniques discussed above will be applied to Xenakis' string quartet, Tetras. This analysis is preliminary, but provides a starting point for developing a detailed and comprehensive understanding of the structural organization of this work. In addition, the analytical tools introduced here should prove useful for many of the other compositions created by Xenakis.

\section{Tetras}

Composed in 1983 for the Arditti String Quartet, Tetras was directly inspired by the awesome virtuosity of this particular group, although some of the textures and instrumental techniques are common to other works for strings by Xenakis from around the same time. ${ }^{36}$ Tetras refers to the Greek work for "four," and Xenakis uses it in the sense of "four in one," 37 with the instruments of the quartet being generally treated as parts of a single entity. For the most part, the music proceeds monophonically, that is one texture at a time, but within that limitation, the technical abilities of the players are stretched to their limits, both in terms of individual parts and ensemble coordination, conveying an overall character of exhilarating virtuosity.

Three basic categories of sonic entities form the starting point for the analysis of Tetras: (1) discrete pitches, (2) glissandi, and (3) unpitched noises. The first entity, the discrete pitches, encompasses a wide range of material, and can be usefully subdivided into three sub-entities: (1a) sustained notes, (1b) scale passages, and (1c) mixed contours. The second, the glissandi, is treated in various ways, but the differences can best be understood in terms of parametrical transformations, and as this entity is always highly recognizable, further subdivisions are unnecessary. ${ }^{38}$ The unpitched noise entity includes a number of different types of sounds, but they are almost always treated as an

35Xenakis describes this conception rather poetically in the Introduction to La légende d'Er: "Music is not a language. A musical work is like a rock of complex formation with streaks and patterns engraved inside and out, which people can decipher a thousand different ways. ..." (La musique n'est pas une langue. Toute pièce musicale est comme un rocher de forme complexe avec des stries et des dessins gravés dessus et dedans que les hommes peuvent déchiffrer de mille manières. ...) Xenakis, "La légende d'Er: geste de lumière et de son," Livret de programme pour Le Diatope (Paris: Centre Georges Pompidou, 1978).

36 Iannis Xenakis, "Un'autobiografia dell' autore raccontata da Enzo Restagno," in Xenakis, ed. Enzo Restagno (Torino: EDT Edizioni, 1988), 59-60. The other works for strings from that period include: Mikka (1971) and Mikka S (1976) for solo violin; Theraps (1976) for solo contrabass; Kottos (1977) for solo 'cello; Ikhoor (1978) for string trio; and Shaar (1983) for string orchestra (all published by Éditions Salabert, Paris).

37 Harry Halbreich, "Da 'Cendrées' a 'Waarg'," 254.

38 Xenakis does make occasional use of a "halting" glissando, in which the finger on the string moves in a stop-start manner while the bow continues to sustain the sound. The result is a kind of "terraced" contour rather than the smooth, continuous contour usually associated with the glissando. This technique, while heard very little in the piece, is of some structural significance, as will be shown later. 
ensemble of entities rather than developed separately, so again, further subdivisions are unwarranted.

On the basis of these preliminary definitions, it is possible to gain an overall impression of the work by tracing the progression (inside-time) of these sonic entities over the whole piece (Fig. 1). The numbers along the top of the diagram indicate beats (there are no bar-lines in the score), and thus provide a measure

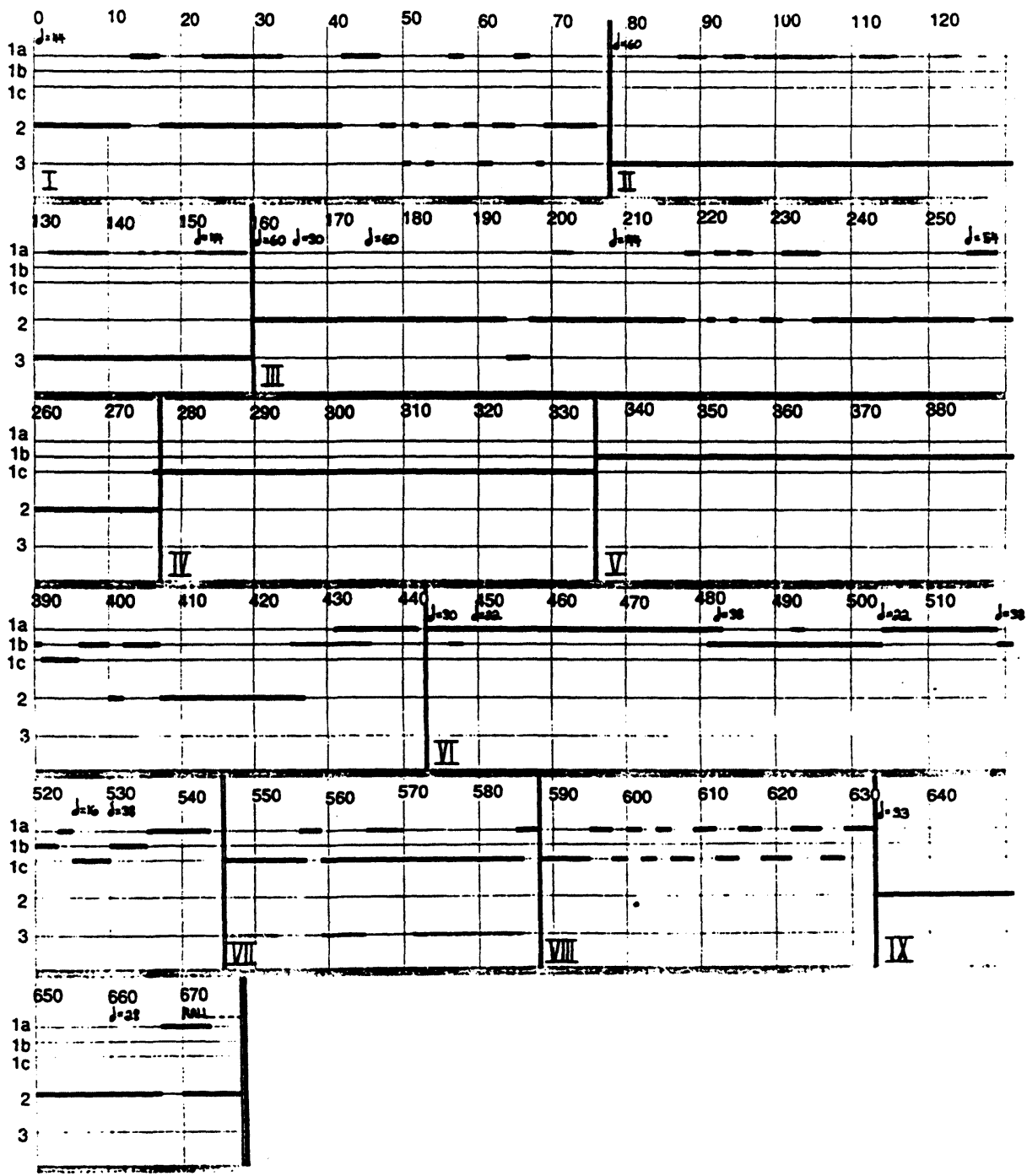

Figure 1: The overall progression of sonic entities in Tetras. 
of the temporal proportions, although there are a number of tempo changes which do alter the time-scale. Black line segments indicate the primary sonic entities; grey line segments indicate occasional secondary sonic entities.

Harry Halbreich, in his discussion of Tetras, subdivides it into nine distinct sections, ${ }^{39}$ which have been included in the diagram (Fig. 1). It can be seen that, for the most part, each section signals a change of sonic entity. An outline of these sections (location in the score ${ }^{40}$ calculated duration, textural description) is given below:

$\begin{array}{rlll}\text { I } & 1-77 & (1: 45) & \text { glissandi } \\ \text { II } & 78-159 & (1: 25) & \text { unpitched noises } \\ \text { III } & 160-276 & (2: 27) & \text { glissandi } \\ \text { IV } & 277-335 & (1: 06) & \text { discrete pitchesmixed contours } \\ \text { V } & 336-443 & (2: 00) & \text { discrete pitchesscale passages } \\ \text { VI } & 444-545 & (3: 50) & \text { discrete pitchessustained notes } \\ \text { VII } & 546-87 & (1: 07) & \text { discrete pitchesmixed contours } \\ \text { VIII } & 588-632 & (1: 12) & \text { discrete pitchesmixed contours/sustained notes } \\ \text { IX } & 633-77 & (1: 45) & \text { glissandi }\end{array}$

Total duration 16:3741

Where the coincidence between the observed structural subdivisions and the shift of sonic entity is not quite so clear (e.g., Section VI), a more detailed consideration of the musical material must be undertaken in order to support this description of the form. In fact, when listening to Tetras, these subdivisions are often far from evident. The reason for this is that the basic sonic entities are made manifest in the music by means of a whole range of parametrical entities, the temporal trajectories of which also contribute to the resultant inside-time structure.

As mentioned above, Xenakis considers the parametrical entities to be part of the outside-time structure of the music. Therefore, in studying a specific work such as Tetras, it is necessary to define the most important of these entities and then to determine how each of them is used in shaping the piece. A summary of these entities is given in Table 1, followed by a discussion of each of them together with examples of how they are applied in the score. The opening passage is examined in detail, and at the end of this section, a graphical representation summarizes this passage in terms of the relevant parametrical entities.

\section{a. Pitch}

Given that only one of the three basic sonic entities in Tetras allows for precise communication of pitch information, it should be clear that traditional analytical methods for examining pitch organization will be of little use. Here, the

39Halbreich, "Da 'Cendrées' a 'Waarg'," 154-55.

40Halbreich errs somewhat in his references to beat numbers in the score. The correct details are given here.

41 The Arditti Quartet perform the piece somewhat faster: Gramavision recording, 15:09; Disques Montaigne recording, 14:35. 


$\begin{array}{ll}\text { pitch: } & \text { register, range, scale } \\ \text { timbre: } & \text { tone-colour, tremolo, trill, pizzicate) } \\ \text { articulation: } & \text { legato, marcato, accented } \\ \text { dynamics: } & \text { fff-ppp } \\ \text { density: } & 1-8(16) \\ \text { synchronicity: } & \text { sonic, parametrical, surface } \\ \text { duration: } & \text { velocity, range (regularity) }\end{array}$

Table 1: A list of the parametrical entities applicable for the analysis of Tetras.

most useful parametrical entities related to pitch are register and range. Register describes the pitch-region within which the music occurs, and range describes the magnitude of that pitch-region. For example, the opening violin solo (Fig. 2a) concentrates on the low register of the violin (the mid-register of the quartet as a whole), and most of the line stays within a range of one octave. However, these parametrical entities also have a dynamic aspect to them, so that, having determined the basic register and range, it can then be seen that the range gradually expands, opening out to cover two octaves (b. 7) before closing in to a very narrow region around a single pitch (Fig. 2b).

As the violin sounds a continuous glissando throughout this passage, perception of precise pitches is rendered impossible. Rather, the listener perceives register, range, and their variations (along with other aspects of the sound, of course). Figure $2 \mathrm{~b}$ shows that Xenakis has created a clear, rather traditionallyshaped phrase, at least in terms of the parametrical entities being discussed here. Note that after the high-point is reached, the range is narrowed sharply, with the glissando then gradually being turned into a trill over a stable pitch. The importance of such transformational processes will be discussed below; suffice it to say here that a connection is thus established between two of the basic sonic entities of the piece.

Within the domain of the discrete pitch entity, Xenakis utilizes another parametrical entity which I call "scale." 42 By this is meant the pitch collection from which the inside-time material is drawn. In Tetras, there are three types of collections used: (1) half-tone ordered scales, where ordered means that specific notes have been selected from the twelve possible pitches per octave (by this definition a diatonic mode would be a half-tone ordered scale); (2) a half-tone chromatic scale (where all twelve pitches per octave can be utilized); and (3) a quarter-tone chromatic scale. The scale entity is an outside-time structure, which means that the inside-time musical material may not necessarily be based on the scale passage entity. In the case of Tetras, there are in

42 "Scale" is here used as a subsidiary, pitch-specific term derived from the more general notion of "sieve" (cf. note 33). 
fact numerous such passages (which accounts for the designation of "scale passage" as a sub-category of the "discrete pitch" sonic entity), but there could be other passages, as in fact there are, which draw on particular pitch collections in order to express different harmonic-intervallic structures. The sustained note (trill) at the end of the violin solo in Fig. $2 a$ is based on the quarter-tone scale, as the trilled note is actually three-quarters of a tone lower than the main pitch. The passage from Section V shown in Fig. 3a offers a clear example of a "scale passage" based on a half-tone ordered scale. The particular

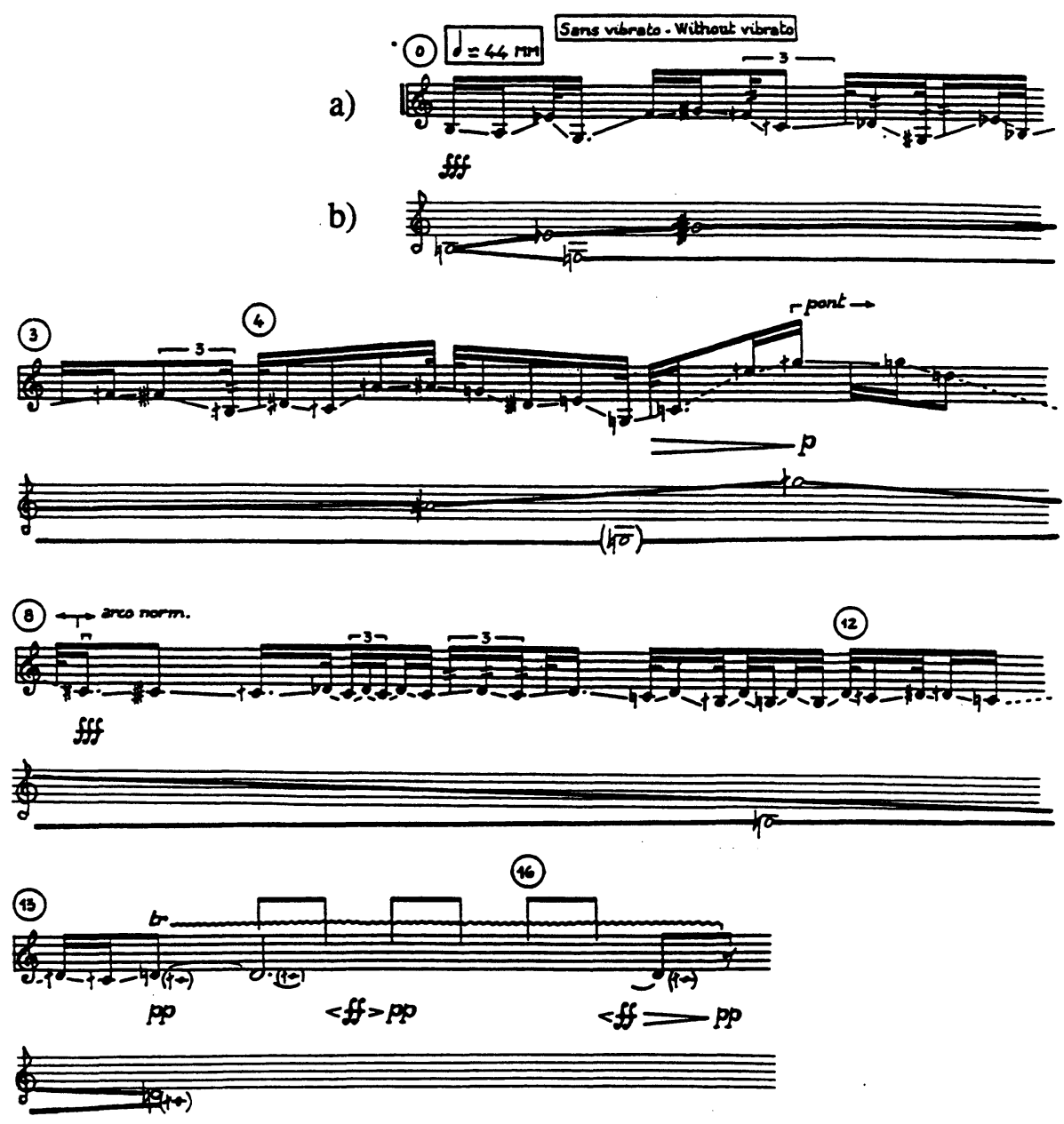

Figure 2: a) The opening violin solo from Tetras (beats 1-17); b) Diagram showing the register and range of the same passage. ( 1983 by Editions Salabert, Paris. All rights reserved. The excerpts of Tetras found in this article are used by permission of the publisher. 

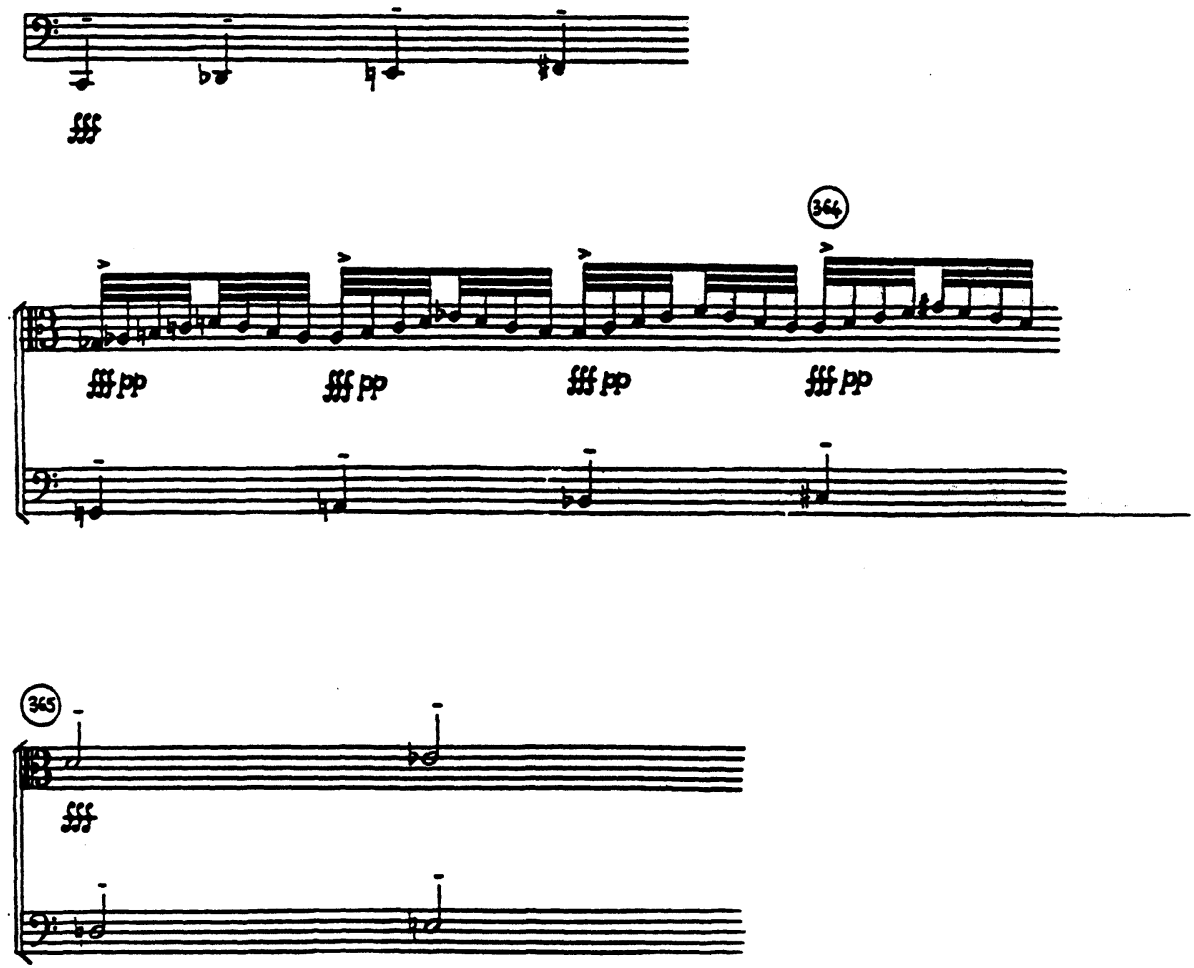

Figure 3a: A scale passage from Section V (beats 336-47).

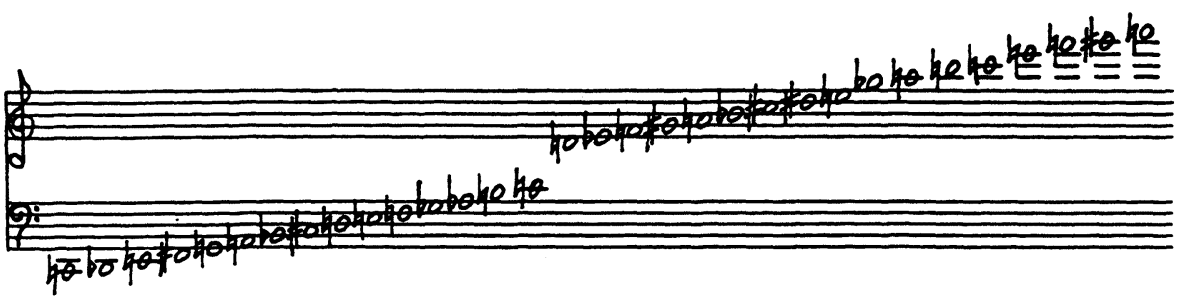

Figure 3b: The non-octaviating ordered scale used in Section V.

scale used here is unusual because it is non-octaviating, that is the ordered intervallic structure does not repeat at the octave (Fig. 3b).

Later in this section, Xenakis makes an explicit connection between the scale-passage entity and the glissando (Fig. 4). Here, the scale material shifts to glissandi and then back again, while other parametrical entities such as register, range, and overall velocity are held constant.

The relationship between these two sonic entities is also hinted at in the use of the "halting" glissando (cf. footnote 37). The perceived effect of this technique is that of a "sliding" scale, a combination of the scale and glissando 

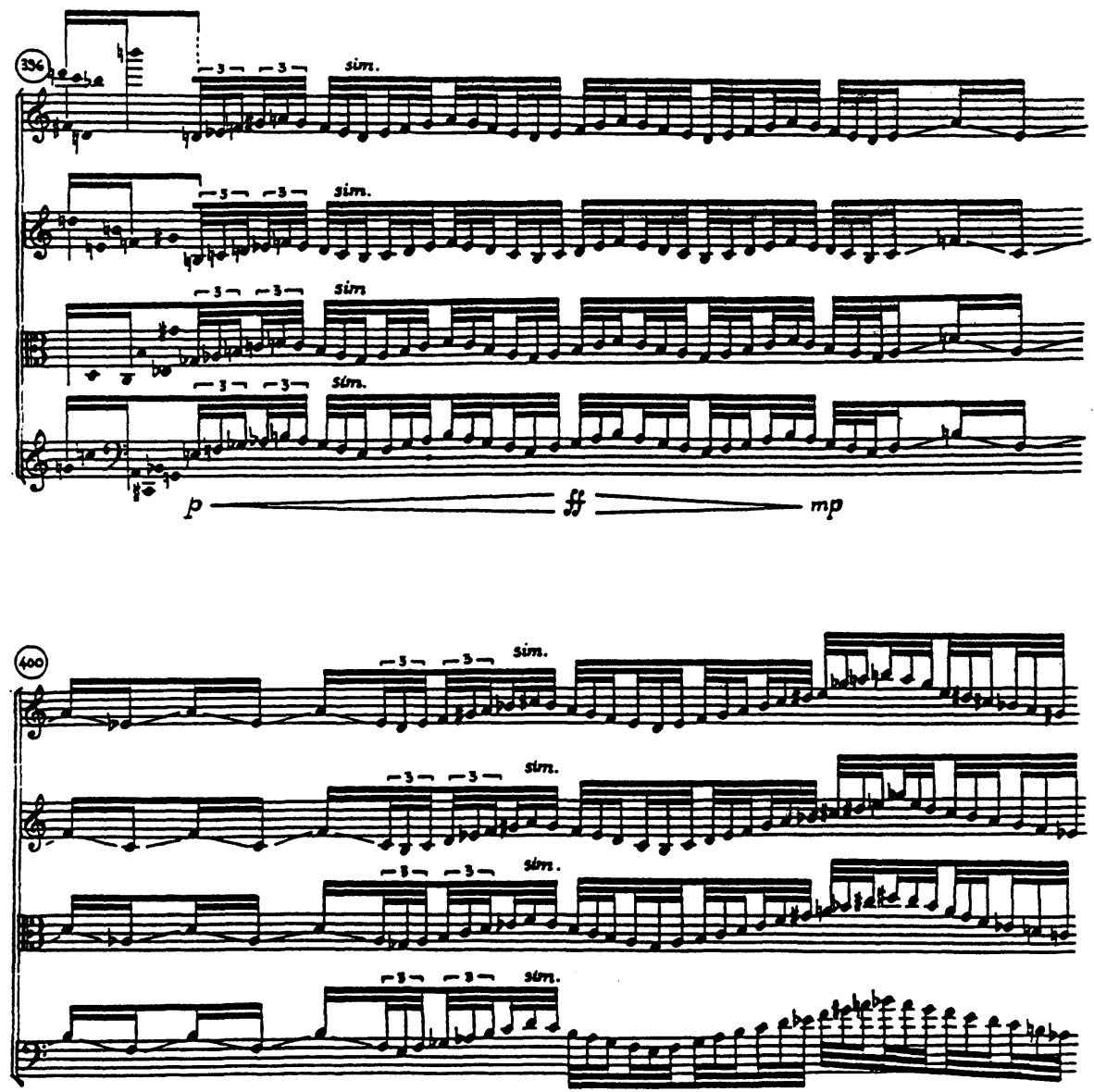

$(m p)$

Figure 4: Scale-glissando alternation from Section V (beats 396-402).

entities (see beats $6 \& 7$ in Fig. 2a for an example, the "halting" glissando being indicated by a dotted line). As mentioned before, Xenakis rarely employs this "sub-entity," but given the ability to establish a connection between the two sonic entities, its use acquires added structural significance.

\section{b. Timbre}

There are a number of parametrical entities which can be grouped under the heading of timbre. The first of these is specifically concerned with sound-quality, and is called tone-colour. The most important manifestation of this entity in Tetras is the sul ponticello effect. ${ }^{43}$ In perceptual terms, this technique of

43Xenakis makes some use of the colouristic possibilities of individual strings on the instruments, such as in the opening passage which is performed on the lowest string of the violin (producing a rich, 
bowing on (or near) the bridge brings out the upper partials of the sound, so much so that the fundamental pitch can become obscured. The opening violin solo offers an interesting example of how this parametrical entity is used (Fig. 2a). At the point where the glissando contour reaches its highest point (beat 7), Xenakis calls for the use of sul ponticello, creating a strong synchronicity between the parametrical entities of range and tone-colour. The timbral shift at that point accentuates the brief excursion into the higher pitch register, helping to delineate this gesture and give shape to the phrase.

The trill can also be considered a timbral entity, a means to ornament sustained pitches. Xenakis makes particular use of it to effect transformations from the glissando entity to the sustained pitch entity, such as in the opening passage discussed above, and in a number of other spots (e.g., beats 65, 222, $225,256)$.

The tremolo is another important timbral entity, elaborating the surface of the music and contributing to the structure of the work. If we look again at the violin solo in Fig. 2a, it will be noticed that the tremolo makes four brief appearances (in beats 1,2,3 and 10), creating a layer of articulation distinct from the contour of the glissando and the interjections of other parameters such as tone-colour and dynamics. In a passage taken from the end of Section II (Fig. 5), Xenakis creates a transition from the unpitched noise entity, which has been predominant throughout this section, to the sustained pitch entity by means of the tremolo and tone-colour parameters.

The strong bow pressure on the string used to produce the "grinding" noise at beat 153 is gradually decreased until a pitched sound is achieved, sul ponticello. At that point, the tremolo is initiated. The effect of the two timbral entities is to create a more complex sound, albeit a pitched one, which serves as a bridge between the two otherwise distinct sonic entities. In Section VIII, Xenakis introduces "measured" tremolos, establishing a link between the timbral and the rhythmical-durational parameters.

Pizzicato could also be included as a timbral entity, but there is only one short passage in which the strings are plucked (beats 525-29). A connection could be established between this entity (a timbral variation of the fixed pitch entity) and the unpitched noise entity, which includes some related soundtypes), but, given the lack of inside-time expressions of it, this relationship is more potential than manifest.

\section{c. Articulation}

String instruments are capable of a great variety of articulation types, but in Tetras, Xenakis limits the field to just three: legato, marcato, and accented. ${ }^{44}$ The first two are not treated as structurally distinct entities, but do contribute

dark sound). However, given that during most of the piece all four instruments are playing at the same time, this rather subtle aspect of tone-colour is lost. It should also be noted that while vibrato could be considered an independent parametrical entity, Xenakis has a strong aversion to it and strictly forbids its use in his music.

44 There is no explicit use of the staccato articulation, but Xenakis does occasionally require the musicians to perform extremely wide intervals at a very fast rate (cf. beats 391-96). This results in a kind of staccato even if the passages are not marked as such. 

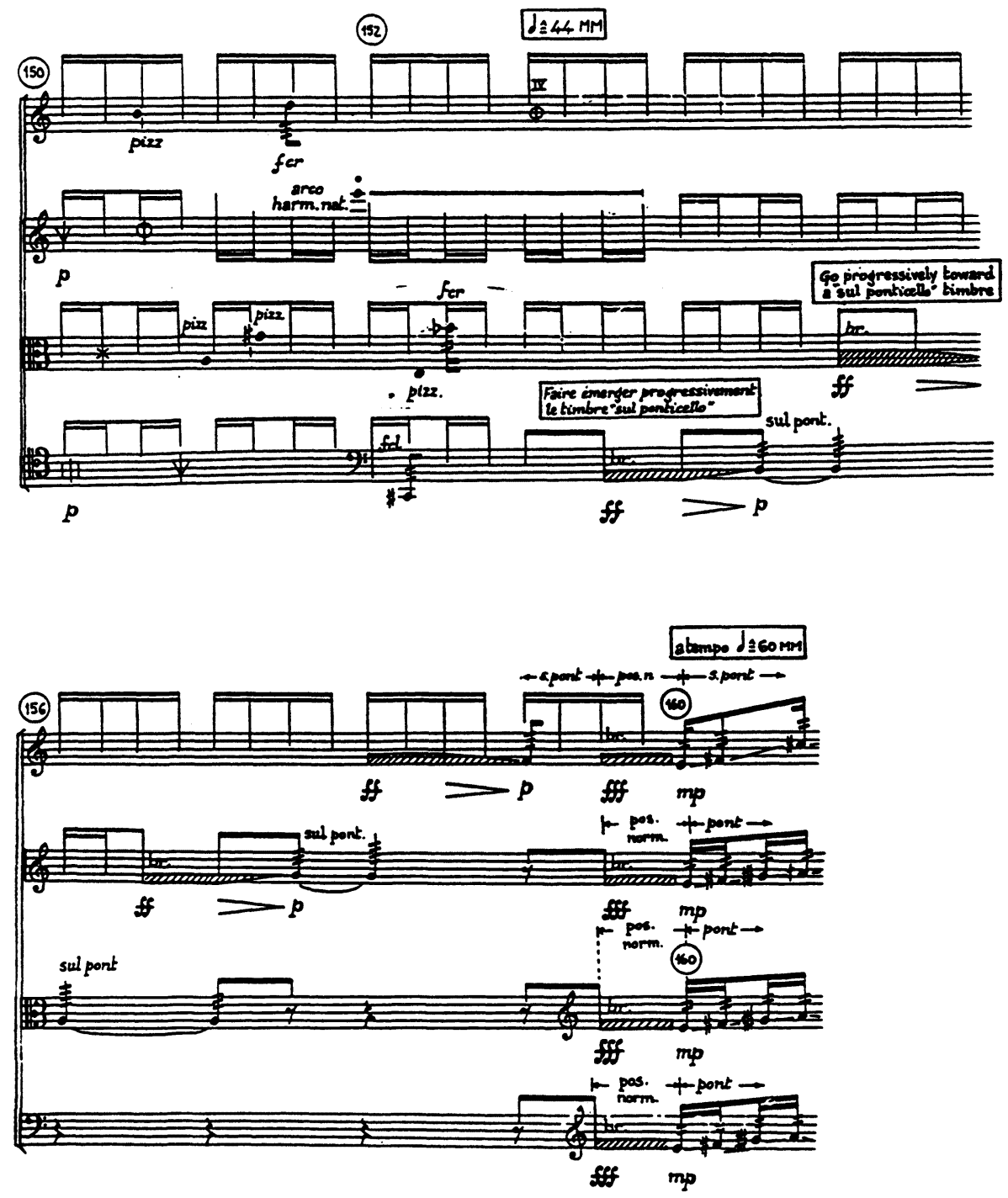

Figure 5: Transition from unpitched noises to sustained pitches (beats 154-59).

to the textural identity of the sonic entities used in the piece. The accented articulation, though, is used to add rhythmic definition to certain textures, particularly the sustained note entity. The first instance of this entity is found in Section I (beats 42-46), where a sustained 8-note chord is animated by a series of irregularly spaced accents articulated by one instrument at a time. Another example of a sustained chord articulated by accents can be found at the end of Section VI (beats 535-43), only in this case the temporal spacing is 
much more regular, and the instruments perform the accents together rather than in a distributed fashion.

The final section of the piece (Section IX) exhibits a confluence of parametrical entities which render explicit a number of connections between different sonic entities (Fig. 6). The accented articulation entity, performed tutti and following a regular rhythmic structure, is combined with the tremolo timbral entity, and these are used to enrich the surface of the basic glissando entity.

The accent entity, perceivable in its own right, regardless of the nature of the material it is being used to articulate, had previously only been used in conjunction with the sustained note entity (discussed above) and the mixed contours entity (just prior to this example, in Section VIII). Therefore, the fact that this parametrical entity is employed here with the glissando entity in a similar fashion to its previous manifestations establishes a relation between these sonic entities. In addition, the accents serrate the contour of the glissando entity in a way that links it to the glissando, the "halting" glissando and the scale passage entities.

\section{d. Dynamics}

The parametrical entity of dynamics is somewhat less independent than the others, being most often used to highlight structural events more strongly articulated by other entities. This is the case in the opening violin solo (Fig. $2 b$ ), where the shift from fff to $p$ and back again coincides with the high point of the pitch-range expansion and also with the timbral change to sul ponticello (beats 6-8). However, in the passage just after that, the changeover from glissando to trill is emphasized by a sudden shift from fff to $p p$ (beat 13). The $s$ witch from one sonic entity to the other might have otherwise been difficult to perceive given that the other parametrical entities (pitch, timbre, articulation) are being held constant throughout. The dynamic fluctuation just after that (beat 14) occurs independently of any other entity and serves as preparation for the viola entry in beat 17 which is triggered by a similar such event.

There are passages in Tetras where the dynamic entity serves as the primary means by which the inside-time structure is articulated. Fig. 7 shows a passage from Section III in which the other parameters affecting the mixed-contour entity are held constant while the dynamics express rather dramatic changes.

It should also be noted that, like the limited number of modes of articulation used, the emphasis in Tetras on dynamic extremes (there is very little use of the dynamic markings $m p$ and $m f$ ) helps to define the particular character (having something to do not only with the kinds of material used but also with the energy and attitude required of the performers) of the work as a whole.

\section{e. Density}

The sense in which the term density is used here refers to the "thickness" of the texture, that is, the number of voices (or, more appropriately, strings) sounding at one time. In the case of Tetras, there is a range of densities from one to eight (the latter being the case of all four instruments playing double- 

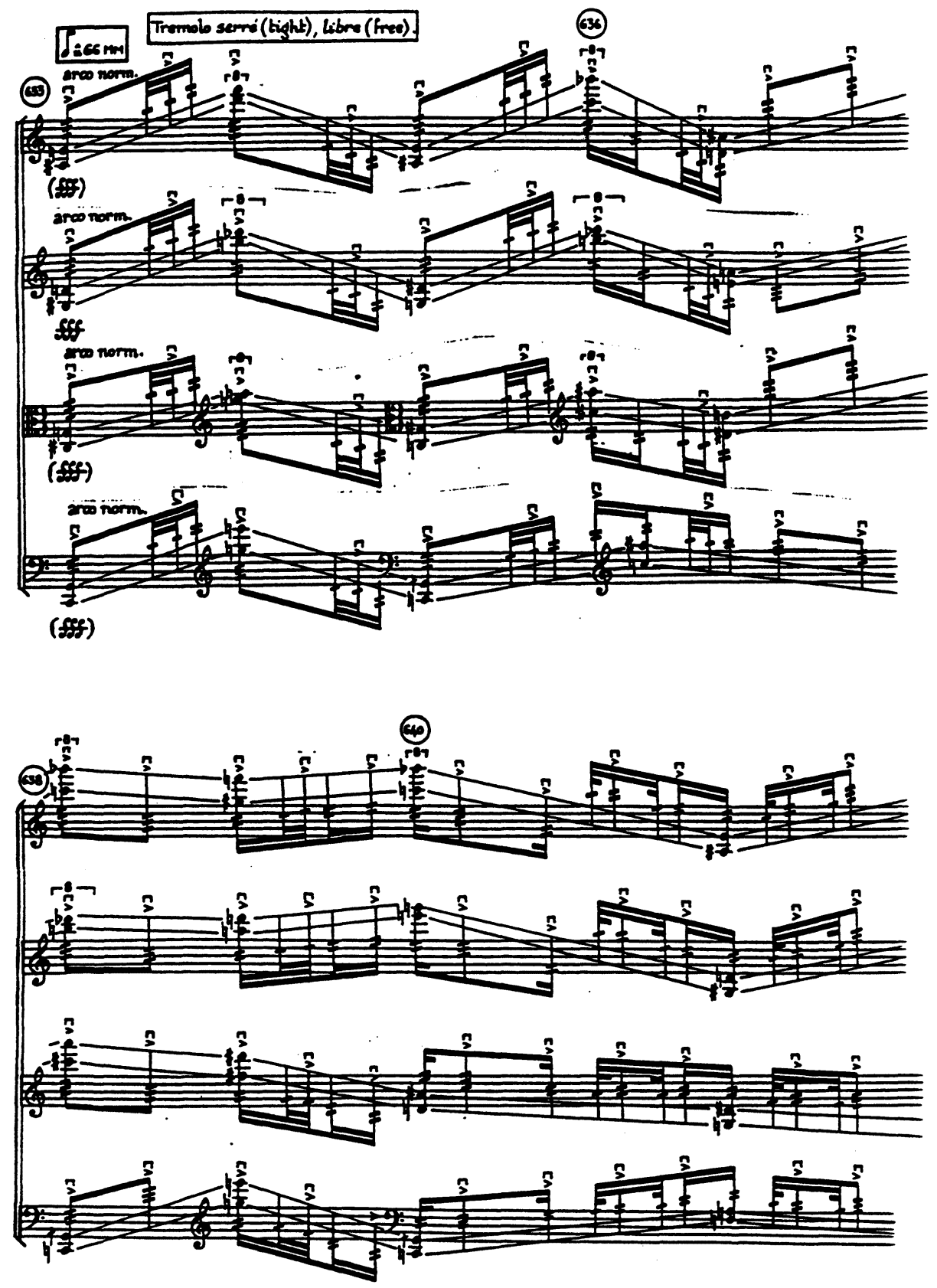

Figure 6: An example of synchronous accents, Section IX (beats 633-42). 
(320)

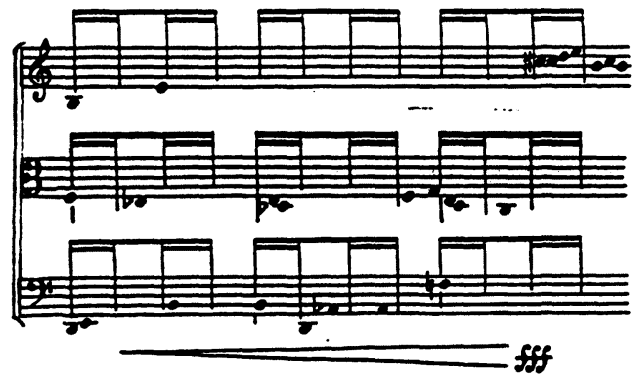

(26)
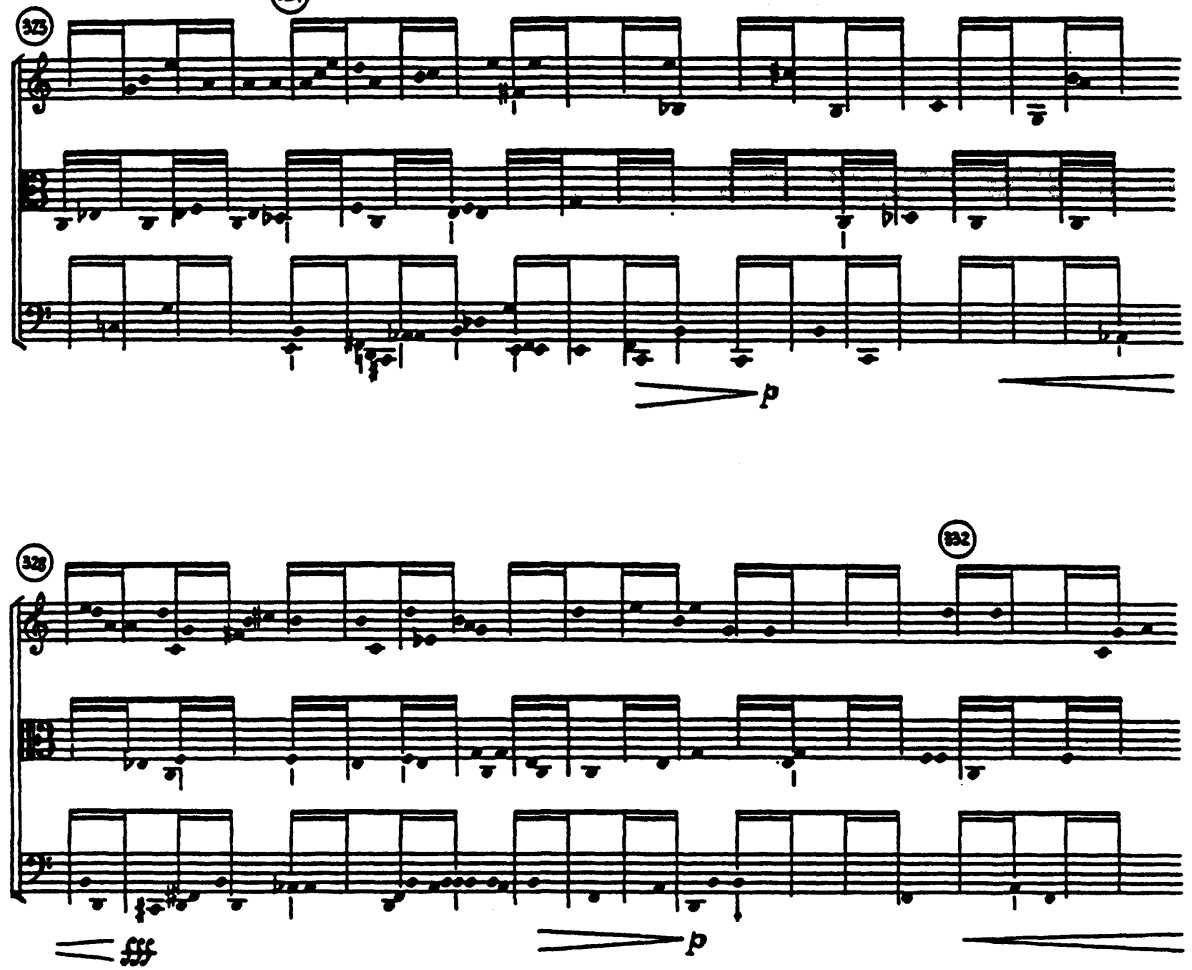

Figure 7: Structural independence of the dynamics entity (beats 322-33). 
stops). ${ }^{45}$ Much of the piece consists of all four instruments playing at the same time (with a density of 4 or 8), so the relatively rare passages of contrasting densities acquire added significance. The opening section (beats 1-47), for example, is based on a linear progression from the violin solo (density of 1) to the viola (double-stops, density of 2 ) to the ensemble (double-stops, density of 8 ). Here though, the trajectory of the density parameter is masked somewhat by the dynamic levels, which move from fff (primarily) at the beginning to ppp at the entrance of the full ensemble.

Throughout the piece there are shifts of density, particularly the inclusion of brief solo passages, which are important for the articulation of the overall form: (1) beat 1 , the violin solo which begins the piece, followed by the viola solo at beat 17 (these are the most extended solo passages of the entire piece); (2) 173-80, a violin solo which echoes the opening, preceded by a brief 'cello solo; (3) 277-82, a violin solo which heralds the beginning of Section IV and a shift from the glissando entity to the mixed-contour entity; (4) 357-64, a slow, deliberate, ascending scale performed by the 'cello near the beginning of Section V (given in Fig. 3a); (5) 389-91, a short violin solo (a continuation of the scale-passage material) which leads to a brief interjection of mixed-contour material, in this case made up of very wide, disjunct intervals; and (6) 559-87, a rare case of a layered texture in which the 1 st violin plays mixedcontour material while the other instruments perform various unpitched noises with occasional interjections of fixed-pitch material.

\section{f. Synchronicity}

There are three types of synchronicities relevant to the analysis undertaken here, this term being taken to mean the degree of coordination between elements of various kinds. The first type, sonic synchronicity, refers to the interplay of contrasting sonic entities (vertically, rather than successively). As already mentioned, Xenakis makes little use of such possibilities in Tetras. The outline of the work given in Fig. 1 shows where these moments of "sonic counterpoint" occur. The most obvious passage is found in Section II, which is primarily based on the unpitched-noise entity, but which also includes high sustained notes sounding intermittently throughout the section. Section VII has already been mentioned in the discussion on density as combining a solo of mixed-contour material with an "accompaniment" of unpitched-noise material. There are also transitional passages in which the instruments move successively from one sonic entity to another, such as the passage given in Fig. 5, or the passage going into Section VI (beats 425-43) which overlaps glissandi with scale figures, and then overlaps those figures with the sustainednote material which dominates Section VI. This transition explains why the diagram in Fig. 1 does not show a clear shift in sonic entities at the start of this

\footnotetext{
45String instruments are able to play triple-stops, but it is not feasible to sustain them much beyond the attack. In any case, Xenakis does not include any triple-stops in Tetras. However, in Theraps for solo contrabass (1976), he actually requires the player to perform unbroken quadruple-stops (normally arpeggiated), a feat demanding enormous strength.
} 
section, and indeed, Section VI could be seen to start at beat 449 , or perhaps at beat 331.46

The second type of synchronicity, parametrical, refers to the interaction of the various parametrical entities as they are manifested inside-time. A number of examples have already been noted in which the different parameters support each other in emphasizing a particular event, or act independently of, or even contrary to, each other (e.g., the coordination of pitch-range, timbre and dynamics at beats 6-8 of the opening violin solo, or the contrast between the decreasing dynamics and the increasing density in Section I).

The third parameter-type is called surface synchronicity, and refers to the "intra-parametrical" coordination of the material. The clearest manifestation of this element can be found in the voice-leading relationships between the instruments when they are playing together. For example, Fig. 6, from the final section of the piece, shows a very strong surface synchronicity, with coordinated dynamics (fff), timbre (tremolo), articulation (accents), register, and range. To begin with, the contours of the glissandi are also synchronous, moving in parallel, but from beat 636, the 'cello part begins to diverge from the others, and then at beat 639 the viola also begins to diverge. By beat 644 , all four parts are pursuing independent contours, although the rhythmic structure (with one small exception in beat 636) remains synchronous. In Tetras, Xenakis draws on the full range of possibilities for synchronizing the instruments in terms of the various parametrical entities, including the use of "imitation," that is the temporal displacement of synchronous material. In Fig. 8 , each instrument in turn is assigned a brief dynamic fluctuation from ppp to $m f$ and back, parametrically synchronized with a timbral shift to sul ponticello and tremolo.

\section{g. Duration}

In a piece such as Tetras, where the glissando entity is very prominent, precise rhythmic perception is often difficult or even impossible, due to the fact that the glissando is a continuous entity. The rhythmic notation for glissandi indicates changes in direction and velocity; these changes, however, are not emphasized by means of articulation or accent. Therefore, a more generalized conception of rhythmic structures needs to be formulated in order to account for the range of materials used by Xenakis. The approach adopted here is similar to the discussion above on pitch, with velocity (instead of register) and range being defined as the basic parametrical entities concerned with duration.

Velocity can be thought of as temporal, or horizontal, density, that is, the number of events per unit of time. Tempo is a controlling factor in regard to velocity, and as can be seen in Fig. 1, there are quite a number of tempo changes over the course of the piece, with the ratio of the slowest to the fastest tempo

46 This analytical quandary underscores my own discomfort with attaching too much "objective" reality to such decisions. The subdivisions of the piece are included for the convenience they afford the discussion. In many instances, the trajectories of the various parametrical entities act to mask the perceptibility of the sections, creating a form more through-composed than might seem from attaching too much significance to these subdivisions. 


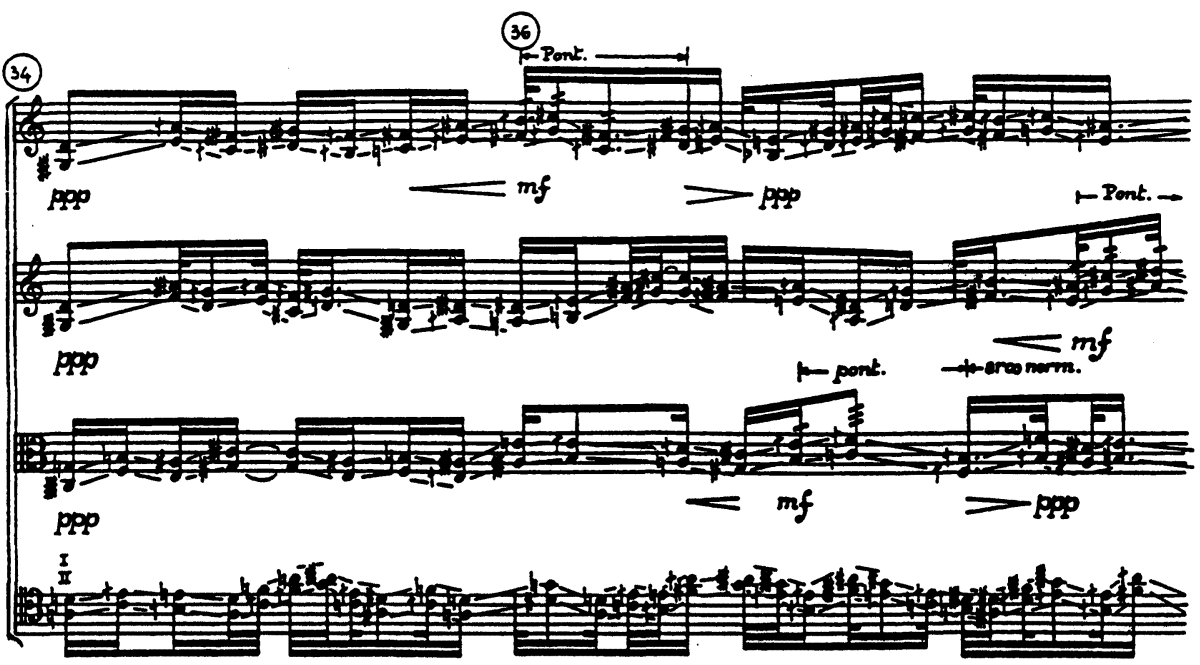

RPP

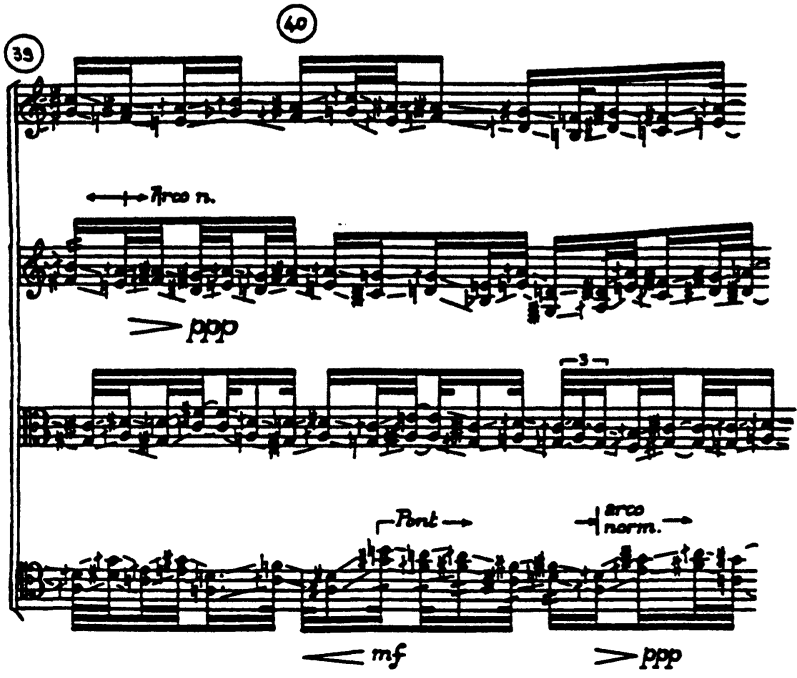

Figure 8: Imitative surface synchronicity (beats $34-41$ ).

being $1: 3.85$, quite a substantial range for a single-movement piece. However, within any given tempo, the resolution of the rhythms is obviously of great importance; the half-notes at the beginning of Section V (quarter-note $=54$ $\mathrm{MM}$ ) produce a much slower velocity than the dense cloud of pizzicato notes (in the order of 25-30 events per beat) heard in the passage with the slowest tempo marking (beats $525-29$, quarter-note $=16 \mathrm{MM}$ ). In general, the velocity is synchronous between the instruments when they are playing together, exceptions 
being found in transitional passages and in layered passages where two sonic entities are heard simultaneously. For example, in Section II, the unpitched noises, all of which are short and percussive, proceed according to a much higher velocity (although it varies over the course of the section) than the sustained notes, which are used sparingly and held for much longer durations.

Range is the parametrical entity which describes the boundaries of durational variability. The opening violin solo (Fig. 2a), for example, shows a range of $1: 7.5$, where the durations are taken from the direction changes of the glissando contour (this ratio does not include the registral expansion at beats $6-8$, which is emphasized with longer durations). The durational range entity is particularly appropriate for those passages in which Xenakis makes use of a "geometric" notation (cf. Fig. 7), where the notes are positioned spatially with respect to subdivisions of the beat. The effect of this technique is to create a global texture (a "mass" or "cloud") in which there are discrete events but no sense of pulse or regular rhythmic structures. In these passages (beats 79-153, unpitched noises; 277-335, discrete-pitch mixed-contours; 391-96, discrete-pitch mixed-contours; 409-19, glissandi; and 525-29, discrete-pitch mixed-contour pizzicati), rhythmic information can only be determined statistically, by means of range (the degree of relative regularity or irregularity between attacks) and velocity (the number of events per beat, taking all the instruments together).

An important sub-class of the range entity can be defined as a restriction to one value only, that is durational regularity. In Tetras, Xenakis attaches particular importance to this rhythmic phenomenon, making use of it in a variety of ways. In Fig. 4, all four instruments are synchronized, playing continuous 32nd-note triplets, and this rhythmic regularity continues through the change to the glissando entity, as the pitch range covered by the glissandi is exactly as wide as it would be if the discrete notes had continued at the same rate. The surface synchronicity of this passage, where the contours of the scale passages and the glissandi are performed in strict parallel by all of the instruments, adds to the relentlessness of the rhythmic organization. In fact, Xenakis explores a range of synchronicities based on durational regularity. In a passage just prior to that shown in Fig. 4 (beats 383-89), the surface synchronicity of the scale material is transformed into a more complex texture by adjusting the pitch range for each instrument so that the scale lengths are different for each, resulting in the parallel motion (the surface synchronicity of the pitch contours) going gradually "out-of-phase" as each instrument follows a cycle of a different length (while the synchronized durational regularity continues). Section VI is based on another possibility, that of having rhythmic structures based on durational regularity proceeding simultaneously at different rates. In Fig. 9, each instrument articulates a four-note chord by means of two contrasting duration-rates. ${ }^{47}$ The overall result is a texture of eight distinct pulses, the individual tempos of which are given in Table 2.

47 I have classified this texture as belonging to the sustained-note entity, given that the pitch content is fairly static, being based on a progression of six 16-note aggregates sometimes connected by passing 


\begin{tabular}{|lcl|}
\hline & $\begin{array}{c}\text { Rhythmic notation } \\
\text { of pulse }\end{array}$ & $\begin{array}{l}\text { Resultant } \\
\text { tempo }\end{array}$ \\
\hline Violin I & $7: 5$ & $123.2 \mathrm{MM}$ \\
Violin II & $5: 4$ & 110 \\
& $3: 4$ & 66 \\
Viola & $4: 5$ & 70.4 \\
& $9: 8$ & 99 \\
'Cello & $8: 8$ & 88 (reference tempo) \\
& $7: 8$ & 77 \\
& $5: 6$ & 73.3 \\
\hline
\end{tabular}

Table 2: List of simultaneous pulse-tempos from Section VI.

Apart from passages of mixed sonic entities or transitions, Xenakis does not explore the possibilities of contrasting the durational ranges between instruments playing at the same time. The range of rhythmic values may be wide through a particular passage, but it is usually the same for all of the instruments (there is one brief exception in beats 361-64, given in Fig. 3a, where the viola ornaments the quarter-note ascending scale in the 'cello with thirty-second note scale figures).

These, then, are the parametrical entities relevant to this analysis of Tetras. Numerous examples have been given in which each outside-time entity has been shown to be structurally important to the inside-time structure of the piece. The question remains, though, as to how an analysis of these entities can be integrated in order to arrive at a global understanding of the work as a whole. This is a difficult task, because of the need to represent the trajectories of all of these parametrical entities together with the sonic entities. Mathematical tools could certainly be used to advantage to quantize analytical information for each unit of time by means of multi-dimensional vectors or matrices. If that were done, a detailed analytical program could be implemented on computer to explore in detail the relationships between all of the various entities. However, given that such an achievement is still some distance away, a graphical representation which portrays the relevant parametrical entities is useful as an interim approach. To that end, a diagram is given below (Fig. 10) which shows the trajectories, or interventions, of the parametrical entities relevant to the opening violin solo of Tetras (note that the duration entity plots the direction changes of the glissando). Most of the correspondences between the entities have already been pointed out, but here they are open to view in a concise manner. 

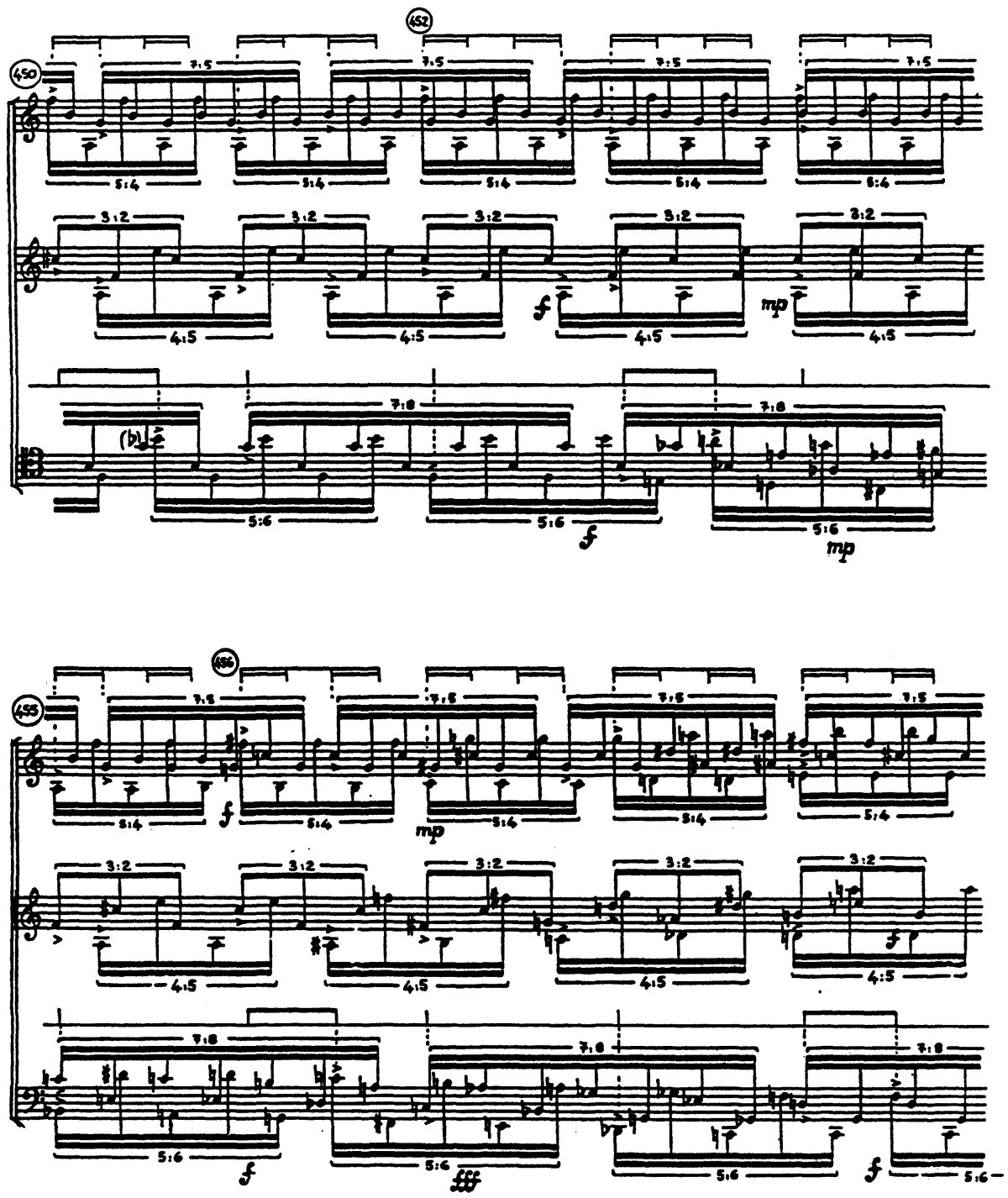

Figure 9: Simultaneous, nonsynchronous pulses (beats 449-54). It is interesting to note that while Xenakis saves this extremely complex rhythmic texture (albeit based on the durational entity of regularity) until Section VI, almost two-thirds of the way through the piece, he does pre-figure it briefly in Section II, where there is a short passage (in the midst of a section otherwise based on irregular "geometric" rhythms) of contrasting simultaneous pulses. 


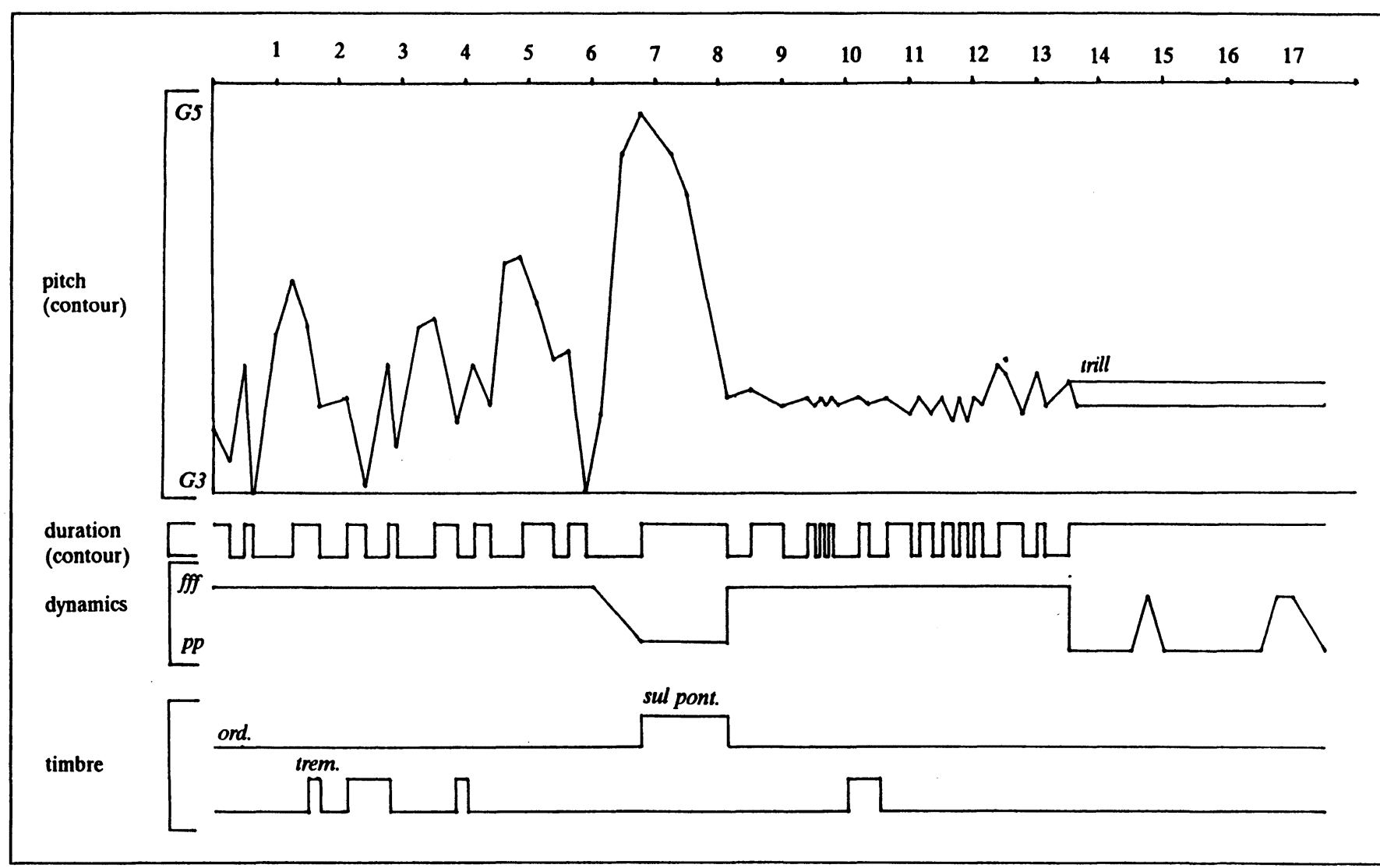

Figure 10: A parametrical summary of the opening violin solo shown in Fig. 2a. 


\section{Conclusion}

The analytical approach outlined here focuses on the outside-time elements of the music, and on how these entities are expressed and combined inside-time. The temporal structure has been less explicitly discussed-the proportions of the various sections and sub-sections of the piece would have to be examined more thoroughly in order to discover the underlying properties of the temporal structure of the work. In terms of the overall form of Tetras, it might be possible to discern a loose ternary form in the progression from the glissando entity which is preponderant at the beginning (Sections $1 \& \mathrm{III}$ ) through the various forms of the discrete pitch entities in the middle (Sections IV to VIII) to the glissando entity which returns at the end (Section IX), with the unpitched noise entity underscoring this closed form by being utilized primarily in two sections, near the beginning and toward the end (Sections II \& VII). However, the treatment of the glissando entity in terms of the parametrical entities is not at all similar between the beginning and the end. The trajectories of the parametrical entities must also be taken into account in determining the overall shape of the form. On that basis it is clear that the form is much more cumulative and organic, as relationships between the various entities, both sonic and parametrical, are established and developed over the course of the piece. However, this process is not a linear one; rather, the outside-time structure, delineated by the particular sonic entities chosen for the work, is linked to the temporal structure on the basis of an array of mathematically-derived processes which result in a complex, nonlinear inside-time structure. The cumulative aspect of the form is perceptual, as the listener gradually builds up an "image" of the musical space inhabited by the piece. This image is based on the progression of the sonic entities, the trajectories of the parametrical entities, and the relationships established between the different entities on the basis of the various combinations, transitions, and juxtapositions which occur and are then established in the listener's memory. It is difficult to summarize one's perception of this form by written or graphic means, but careful study of the music on the basis of the principles described above will undoubtedly aid the cognitive process of analysis, whatever form the results may take.

Even though the analytical application undertaken here has focused on one work, Tetras, it is my contention that this approach will be relevant for other compositions by Xenakis, and indeed, that it can be usefully employed for most, or perhaps even all, of his mature works. ${ }^{48}$ The sonic entities must be determined for each work on the basis of aural familiarity with the music. It may also be necessary to define additional, or different, parametrical entities or sub-entities (for example, in an orchestral piece the orchestration may well be of sufficient importance to merit consideration as a separate entity rather than a sub-entity of timbre or density). What is clear, in any

48 The earlier version of this article, presented at the CUMS Annual Conference in 1993, included an analytical discussion of Tetora (1990) for string quartet. This approach also proved helpful in preparing a review of a new recording of five chamber works. See James Harley, "Xenakis [record review]," Tempo: A Quarterly Review of Modern Music 184 (March 1993): 47-48. 
case, is that Xenakis continues to think about composition in the same terms he expounded in Formalized Music in the 1960s. As he stated in an interview recently, "the question of global structure and of timbre comes to the forefront." 49

The first part of this article outlines the historical and technical background for the particularly unique musical aesthetic which Xenakis has worked to communicate through his music. A discussion of the theoretical concepts and compositional tools he has developed, though, should not overlook the creator's intuition. ${ }^{50}$ There is an element of creativity that goes beyond the rational intellect, an element of musical expression that cannot be conveyed in any way except in music:

I do not think that abstract schemes are of any interest whatsoever. To make use of this or that abstract model and to reproduce it in music, in painting or in cinema, is a guide; but, if there is only this guide, it indicates an idleness of spirit. ... In reality the ongoing process of creation must reject abstraction. ${ }^{51}$

My work is not governed by rationality alone ... I only speak about what I can speak about ... I reach [for] the inaccessible through music. ${ }^{52}$

\begin{abstract}
From his earliest works, Xenakis has conceived his music in terms of textures and sound masses. The analytical approach introduced here for a study of the recent string quartet, Tetras, takes such sonic entities as its point of departure. The inside-time structure is described in terms of the temporal succession of these entities and the outside-time relationships established between them by means of a whole range of parametrical entities. While the sonic and parametrical entities need to be specified for each piece, it is shown that this approach can be profitably applied to the complete Xenakis oeuvre.
\end{abstract}

49 "le questioni di struttura globale e di timbro vengono in primo piano." Xenakis, "Un'autobiografia dell'autore," 61.

50 "[T] he solution is not really calculated or computed, but is a thought-out intuitive approach...with all previous experience as an aid." Simon Emmerson, "Xenakis [interview]," Music \& Musicians 24 (May 1976): 24.

51 "Je ne pense pas que les combinaisons abstraites soient d'aucun interêt. Utiliser tel ou tel modele abstrait et le reproduire en musique, en peinture ou en cinématique, c'est un guide; mais, s'il n'y a que ce guide, c'est une paresse de l'esprit. ... En réalité la création perpétuelle devrait rejeter l'abstraction." Jacques Bourgeois, Entretien avec Iannis Xenakis (Paris: Boosey and Hawkes Music Publishers, 1969), quoted in Denys Bouliane, "Les Journées Mondiales de la Musique 1987," Sonances 7, no. 4 (1988): 36.

52 "Je ne fais pas une oeuvre rationaliste. ... [J]e ne parle que de ce dont je peux parler. ... L'inaccessible, je l'atteins par ma musique." Xenakis, "Entretien IV: rationalité et impérialisme [avec François-Bernard Mâche]," l'Arc 51 (1972): 58 (reprinted in Xenakis, Musique, Architecture [Paris: Casterman, 1976]). 